Case Study

\title{
CORTICOSTERIODS INDUCED ECCHYMOSIS
}

\author{
JOSHISREE K. P. ${ }^{* 1}$, RAJESH G. ${ }^{1}$, SIDDARAMA R. ${ }^{1}$ \\ 1,2Department of Pharmacy Practice, Creative Educational Society's College of Pharmacy, N H 4, Chinnatekur, Kurnool, Andhra Pradesh, \\ India 518218 \\ Email: joshi5kopperla@gmail.com \\ Received: 24 Aug 2017 Revised and Accepted: 22 Nov 2017
}

\begin{abstract}
Corticosteroids are the steroid hormones which are mainly used in the treatment of various diseases like rheumatoid arthritis, osteoarthritis, rheumatic fever, gout, allergic reactions, renal diseases and haematological diseases. Prolonged use of corticosteroids causes a number of undesirable effects. Major adverse drug reaction (ADR's) includes ulcers/gastrointestinal bleeding, osteoporosis, increased risk of heart diseases and decreased in bone density. Here we report a case of male patient of 72years old who was confirmed with cervical osteoarthritis and using oral corticosteroid (OCS) (methylprednisolone) since $6 \mathrm{y}$. While the patient was on therapy ecchymosis was noticed. The relation between suspected drug and ADR was established by performing ADR assessment scale, whereas both de-challenge and re-challenge was done, and ADR assessment scales like Naranjo's scale, WHO UMC scales showed probable ADR, it can be managed by stopping the drug or using alternative days. Close monitoring of blood cortisol levels in a patient using oral corticosteroids (OCS) should be done.
\end{abstract}

Keywords: Oral Corticosteroids, Methylprednisolone, Ecchymosis

(C) 2018 The Authors. Published by Innovare Academic Sciences Pvt Ltd. This is an open-access article under the CC BY license (http://creativecommons.org/licenses/by/4.0/) DOI: http://dx.doi.org/10.22159/ijpps.2018v10i1.22212

\section{INTRODUCTION}

Ecchymosis is described as a large zone of skin discolouration caused by extravasation of blood into the subcutaneous tissue of the body. The onset discolouration of the skin is caused by the escape of the blood from ruptured blood vessels into the capillaries. Discolouration and exact colour of the skin represents the physiologic sequel of haemoglobin catabolism which is converted into bilirubin and hemosiderin. Ecchymosis is a common adverse effect associated with prolonged corticosteroid therapy. Senile purpura and corticosteroid-induced ecchymosis are similar and appear as large purple/brown blotches on the neck, face, or exterior surfaces of the arms and hands [1]. The pathophysiological mechanism of corticosteroid-induced ecchymosis is, after prolonged use of methylprednisolone leads to the destruction of the collagen support for small blood vessels which results in leakage of blood into surrounding tissues [2]. Prolong use of OCS also causes ulcers/gastrointestinal bleeding, osteoporosis, increased risk of heart disease and a decrease in bone density.

Incidence: 22,909 people reported to have side effects when taking methylprednisolone. Among them, 57 people $(0.25 \%)$ have ecchymosis [3]

\section{CASE REPORT}

A 72 y old male patient admitted in cardiology department with chief complaints of severe neck pain, and brown blotches on exterior surfaces of both hands [persistent] since 2 mo, chest pain associated with sweating since $1 \mathrm{~d}$. He was a known patient with cervical osteoarthritis [spondylitis] and he was using Methylprednisolone since $6 \mathrm{y}$. On general examination patient was conscious and coherent, his vitals shows blood pressure $100 / 70$, pulse rate $84 \mathrm{bpm}$, respiratory system (RS) shows clear.

\section{Investigations}

Laboratory examinations showed, haemoglobin $13.9 \mathrm{gm} / \mathrm{dl}$, WBC 12000 cells/cum, blood urea $38 \mathrm{mg} / \mathrm{dl}$, serum creatinine $1 \mathrm{mg} / \mathrm{dl}$, ESR $18 \mathrm{~mm} / \mathrm{hr}$, SGOT 258u/l, SGPT $65 \mathrm{u} / \mathrm{l}$, electrolytes shows sodium $138 \mathrm{mmol} / \mathrm{l}$, potassium $3.9 \mathrm{mmol} / \mathrm{l}$, chloride $130 \mathrm{mmol} / \mathrm{l}$, RBS $142 \mathrm{mg} / \mathrm{dl}$, total cholesterol $285 \mathrm{mg} / \mathrm{dl}$, triglycerides $269 \mathrm{mg} / \mathrm{dl}$, HDL 48.7 mg/dl, VLDL 53 mg/dl, LDL 146.8 mg/dl, CKMB 170 u/l, His serology tests showed negative.2D ECHO (EF 40\%) shows coronary artery disease with moderate left ventricular dysfunction and ECG showed right bundle branch block (RBBB), antero-septal MI, T wave abnormality with possible anterior ischemia. Based on subjective and objective evaluation patient was experienced corticosteroid (Methylprednisolone) induced ecchymosis. Clinical evaluation was done and patient was treated symptomatically with Tab clavix+aspirin $(75+325 \mathrm{mg}$ )(for CAD), tab atorvastatin 40 $\mathrm{mg}($ lipid lowering), tab ranitidine $150 \mathrm{mg}$ (antacid), tab methylprednisolone $2 \mathrm{mg}$ (for ecchymosis), and tab aceclofenac (for pain).

\section{ADR analysis}

\section{Causality assessment}

After collecting past and present history of the patient, ADR analysis is done by using Naranjo's scale, WHO-UMC scale, karch and lasagne scales shown in table 1 , and the most suspected drug to produce ecchymosis due to OCS. Here we also performed severity, predictability and preventability scales shown in table 2 .

\section{Re-challenge}

Patient has similar complaints from past, for confirmatory purpose we had reintroduced drugs methylprednisolone and aceclofenac+ tramadol, then he had experienced same symptoms like brown blotches on exterior surfaces i.e. in both hands.

\section{De-challenge}

After completion of the evaluation of re-challenge of suspected drugs were administered alternative days as he was with cervical osteoarthritis.

\section{DISCUSSION}

Corticosteroids (methylprednisolone) belongs to the class adrenal glucocorticoids. Mechanism shows it is a synthetic glucocorticoid, has potent anti-inflammatory activity in disorders of many organ systems and has sodium-retaining properties. It decreases the inflammatory cytokine cascade, inhibiting the activation of $\mathrm{T}$ cells, decreasing the extravasation of immune cells into the central nervous system, facilitating the apoptosis of activated immune cells, and indirectly decreasing the cytotoxic effects of nitric oxide and tumour necrosis factor alpha [2]. 
The mechanism of corticosteroids induced ecchymosis is the destruction of the collagen support for small blood vessels which results in leakage of blood into surrounding tissues. Common symptoms of ecchymosis skin lesions shows petechial-small type of hematoma, pigmented purpuric dermatosis [2].

Few reports showed extensively with the occurrence of purpura, spontaneous ecchymosis or easy bruising after the administration of these corticosteroid hormones. Such skin lesions were noted in patients with arthritis who are receiving corticosteroids [4].
OCS causes numerous side effects like Cushing's syndrome, peptic ulcer disease, osteoporosis, heart diseases like congestive heart disease (CHD).

The duration of corticosteroids therapy in these conditions is often less than $1 \mathrm{mo}$, in contrast to the treatment of chronic respiratory diseases (asthma and Chronic obstructive pulmonary disease COPD), or autoimmune diseases (rheumatoid arthritis, systemic lupus erythematous, crohns disease and ulcerative colitis which can last for years [5].

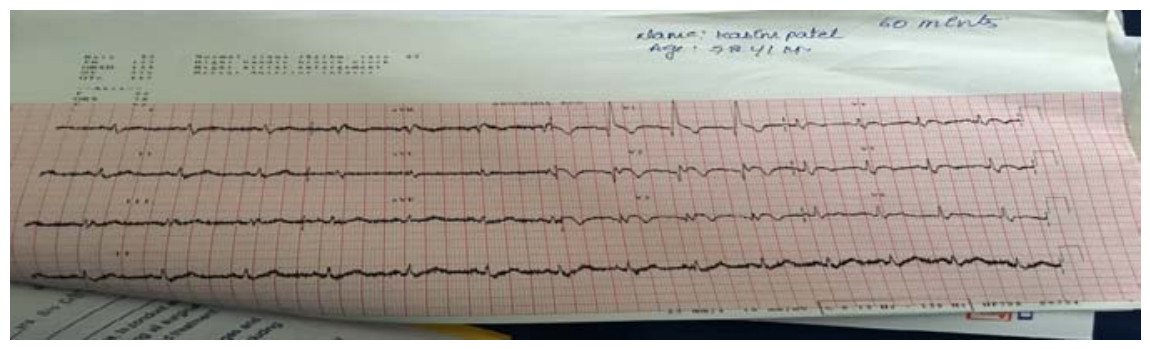

Fig. 1: ECG shows right bundle branch block

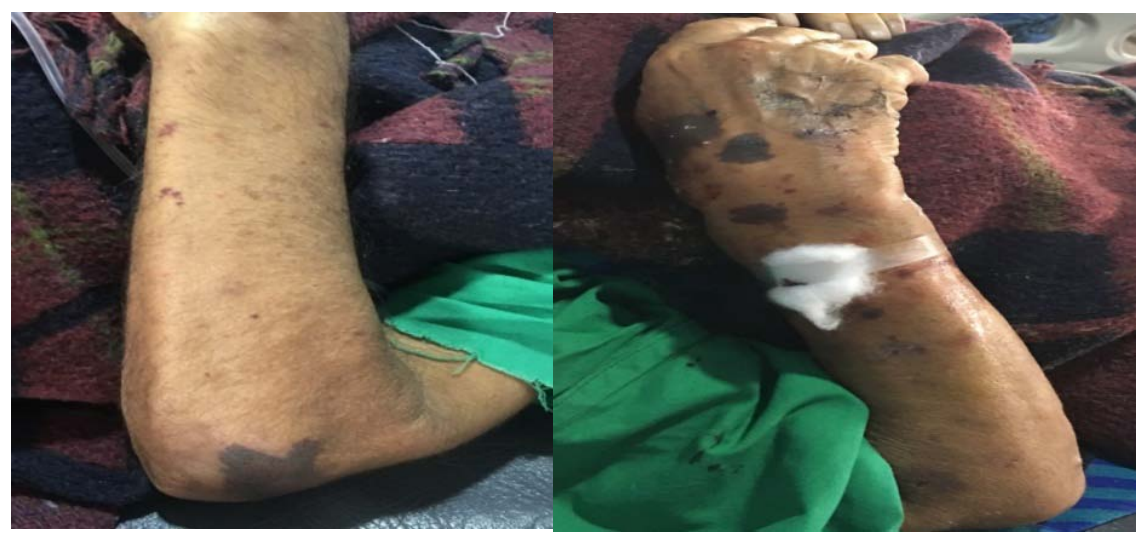

Fig. 2: Showed ecchymosis on both hands

Table 1: Causality assessment scale

\begin{tabular}{llllll}
\hline S. No. & Suspected drug & Suspected ADR & Naranjo's scale & WHO UMC & Karchand lasagna \\
\hline 1. & Corticosteroid (methylprednisolone) & Ecchymosis & Probable ADR (6) & Probable ADR & Probable ADR \\
\hline
\end{tabular}

Table 2: Severity, predictability and preventability of suspected ADR

\begin{tabular}{llll}
\hline ADR & Drug & Severity & Predictability \\
\hline Ecchymosis & Methylprednisolone & Severe level 4 & Unpredictable ADR \\
\hline
\end{tabular}

\section{CONCLUSION}

Daily use of corticosteroids (methyl-prednisolone) causes ecchymosis skin lesion in some patients. As corticosteroids may cause serious adverse effects, the Clinical pharmacist should play a major role in detecting, monitoring and managing of ADRs. Reducing the dose of the corticosteroids or using alternative day dosing may decrease the lesions effects. Precautions should be taken and proper monitoring of blood cortisol levels and WBC level for patients who receive OCS should be done.

\section{AUTHORS CONTRIBUTIONS}

K P Joshisree-Followed the case, wrote the case study

G Rajesh-Took a detailed history of the patient

R Siddarama-helped in structuring the paper

\section{CONFLICT OF INTERESTS}

Declared none

\section{REFERENCES}

1. Milijankrcobic, ecchymosis, drug details; 2017. Available from: https://drugsdetails.com/ecchymosis-definition-types-symptomscauses-diet-and-treatments-pictures/. [Last accessed on 16 Jul 2017].

2. Methylprednisolone, Micromedex, truven health science. Available from: http://www.micromedexsolutions.com/ micromedex2/librarian/CS/FC2649/ND_PR/evidencexpert/ND_P/e videncexpert/DUPLICATIONSHIELDSYNC/18B90D/ND_PG/evi dencexpert/ND_B/evidencexpert/ND_AppProduct/evidencexp ert/ND_T/evidencexpert/PFActionId/evidencexpert.DoIntegra tedSearch?SearchTerm=MethylprednisoloneandfromInterSaltB 
ase $=$ trueandfalse $=$ nullandfalse $=$ nulland $=$ null $\# . \quad$ Last accessed on 16 Jul 2017].

3. Methylprednisolone and ecchymosis from FDA reports, eHealth ME. Available from: http://www.ehealthme. Com/ ds/methyl-prednisolone/ecchymosis/.[Last accessed on 13 Oct 2017].
4. Charles W Denko, MD Leslie R. Schroeder MD. Ecchymotic skin lesions in a patient receiving prednisolone: The Jama Network; 1957. p. 41-3.

5. David M, Poetker MD MA, Douglas D, Reh MD. A comprehensive review of the adverse effects of systemic corticosteroids. Otolaryngol Clin North Am 2010;43:753-68. 